\title{
Impact of Prophylactic Betamethasone Indication on the Neonatal Outcome in 38-Week Pregnancies Prior to Elective Cesarean Section
}

\author{
Enrique Valdés Rubio1,2*, Pamela Socías', Javiera Urquieta1, Enrique Valdés M², \\ Alvaro Sepúlveda-Martínez ${ }^{1}$

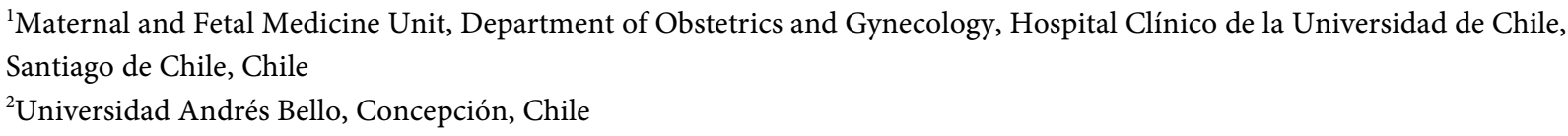

How to cite this paper: Rubio, E.V., Socías, P., Urquieta, J., Enrique Valdés M and Sepúlveda-Martínez, A. (2020) Impact of Prophylactic Betamethasone Indication on the Neonatal Outcome in 38-Week Pregnancies Prior to Elective Cesarean Section. Open Journal of Obstetrics and Gynecology, 10, 1396-1401.

https://doi.org/10.4236/ojog.2020.10100128

Received: April 23, 2020

Accepted: October 11, 2020

Published: October 14, 2020

Copyright $\odot 2020$ by author(s) and Scientific Research Publishing Inc. This work is licensed under the Creative Commons Attribution International License (CC BY 4.0).

http://creativecommons.org/licenses/by/4.0/

\section{(c) (i) Open Access}

\begin{abstract}
Objective: To assess whether the use of prenatal betamethasone in pregnancies with elective Caesarean section (C-section) at 38 weeks has a similar risk of adverse neonatal respiratory outcomes than elective C-section at 39 weeks. Methods: Retrospective cohort study of pregnant patients with singleton pregnancies and elective $\mathrm{C}$-section at term in a one-year period. Cases were C-section at 38 weeks of gestation with a complete course of betamethasone started 48-hours before. As a control group, pregnancies with a C-section at 39 weeks without betamethasone were included. Results: During the study period, 186 patients were included. Of these, 91 were delivered at 38 weeks and 95 at 39 weeks. There were no significant differences in maternal age and parity. Moreover, there were no significant differences in respiratory complications (respiratory distress syndrome $[\mathrm{RDS}]=0 \%$ vs $1.1 \% ; \mathrm{p}=1.0$, transitory tachypnea $[\mathrm{TT}]=0 \%$ vs $0 \%$ ) and admission to Neonatal Intensive Care Unit (NICU) ( $8.8 \%$ vs $6.3 \%$; $\mathrm{p}=0.7$ ) between deliveries at 38 weeks and 39 weeks, respectively. Conclusion: Prophylactic use of betamethasone in early term pregnancies who undergo an elective C-section at 38 weeks is associated with similar adverse neonatal respiratory outcomes than patients with C-section at 39 weeks without corticosteroids.
\end{abstract}

\section{Keywords}

Betamethasone, Corticosteroids, Elective Cesarean Section, Respiratory 
Complications, Respiratory Distress Syndrome, Transitory Tachypnea

\section{Introduction}

The administration of corticosteroids prior to preterm birth has proven to be one of the indications with greatest impact in neonatal outcome. The American College of Obstetricians and Gynecologists (ACOG) [1] recommends its use when there is a threatened preterm labor before 34 weeks of pregnancy. Recently, ACOG also recommends its use in late premature births $\left(34^{+0}-36^{+6}\right.$ weeks $)$ based on a study that concludes that this indication significantly reduces severe respiratory complications $(12.1 \%$ vs. $8.1 \%, \mathrm{p}<0.001)$ [2].

Interestingly, elective cesarean sections are associated with a higher risk of respiratory morbidity even in term pregnancies. Thus, neonatal morbidity has been shown to be higher in newborns whose mothers were delivered by elective cesarean section at different gestational ages [3]-[10]. In this line, the ASTECS study concluded that the prophylactic administration of betamethasone in term pregnancies (38 or more weeks) 48 hours prior to an elective cesarean section reduced TT and RDS requiring admission to the NICU versus the control group (relative risk $\mathrm{RR}=0.46,95 \%$ confidence interval $=0.23-0.93$ ) [9].

Despite these results, the Cochrane Library suggested that more studies are needed to share valid conclusions [3]. Therefore, there is still controversy on whether the indication of corticosteroid has a beneficial effect on neonatal respiratory outcomes when indicated at 38 weeks in pregnant women who undergo an elective cesarean section [4]-[10]. The present study aims to evaluate if the prophylactic use of betamethasone in patients with elective cesarean section at 38 weeks is associated with similar neonatal respiratory outcomes than cesarean section at 39 weeks without betamethasone.

\section{Methods}

\subsection{Study Design}

This retrospective case-control study was carried out at the Delivery and Neonatal Units of the Department of Obstetrics and Gynecology from Hospital Clínico de la Universidad de Chile between 2017 and 2018. Maternal, perinatal and neonatal variables related to respiratory morbidity and admission to NICU, were collected and stored in a dedicated database. Cases were patients with elective cesarean section at 38 weeks with prophylactic use of antenatal betamethasone ( 2 doses of $12 \mathrm{mg}$ with a 24 hour-interval), and controls those with an elective C-section at 39 weeks without corticosteroids.

\subsection{Patient's Selection}

Included were patients with singleton pregnancies, with indication of elective 
cesarean sections due to mild intrahepatic cholestasis of pregnancy, previous cesarean section, total occlusive placenta with signs of placenta accreta, multiple cesarean section scars associated with rurality and late-onset pre-eclampsia. $\mathrm{Pa}$ tients with onset of labor before cesarean section, emergency delivery, multiple pregnancies, gestational diabetes or maternal contraindication of corticosteroids were excluded.

\subsection{Outcomes}

In this study, the primary outcome was the neonatal respiratory distress syndrome, which was defined as the presence of tachypnea, cyanosis, intercostal retraction and pathognomonic radiological signs in a newborn, with clinical signs of oxygenation compromise [11].

Secondary neonatal outcomes include transient tachypnea, birth weight, APGAR less than 7 at 5 minutes, hypothermia, neonatal jaundice, and NICU admission.

Transient tachypnea was defined as the presence of tachypnea (100 - 120 breathings per minute) with clinical signs of breathing dysfunction from newborn period until 2 hours after delivery, with self-limited improvement [11]. Hypothermia was defined according to the World Health Organization definition, as body temperature below $36.5^{\circ}$ Celsius $\left(97.7^{\circ} \mathrm{F}\right)$ in the newborn. [12]. Neonatal jaundice was defined as any yellow discolouration of the skin or sclera in the newborn [13]. For this study, the newborns with any grade of serum bilirubin based on days from birth that required hospitalized treatment, were included.

\subsection{Statistical Analysis}

For all statistical analyses, the dedicated software Stata v14.0 (College Station Tx, USA) was used. Categorical variables were compared with Fisher exact or chi2 test and expressed as percentages. Continuous variables distribution was assessed with Shapiro-Wilk test and compared with t-test or Mann-Whitney U for parametric and non-parametric distribution, respectively.

For this study, a p-value less than 0.05 was considered as significant.

\section{Results}

During the study period, 186 patients were included. Of these, 91 patients delivered at 38 weeks with previous betamethasone and 95 patients were delivered at 39 weeks. There were no significant differences in maternal age (33.9 vs. 32.0; p $=0.13)$, nulliparity ( $32.0 \%$ vs. $29.6 \% \mathrm{p}=0.13$ ) or body mass index (30.8 vs. 31.9 ; $\mathrm{p}=0.17)$. Table 1 shows that the only significant differences were gestational age and birth weight. These results were expected by the study design.

Regarding neonatal respiratory outcome, there were no significant differences in $\mathrm{RDS}(0 \%$ vs. $1.1 \% ; \mathrm{p}=1.0)$ nor TT $(0 \%$ vs. $0 \%)$. NICU admission rate at 38 weeks was $8.8 \%$ vs. $6.3 \%$ at 39 weeks of gestation $(p=0.7)$. 
Table 1. Maternal characteristics and neonatal respiratory outcome.

\begin{tabular}{cccc}
\hline Variable & $\begin{array}{c}38 \text { weeks } \\
\text { With corticosteroids } \\
(\mathrm{n}=91)\end{array}$ & $\begin{array}{c}\text { Without weeks } \\
(\mathrm{n}=95)\end{array}$ & p-value \\
\hline Maternal age, years & $33.9 \pm 5.1$ & $32.0 \pm 6.2$ & 0.13 \\
GA at delivery, weeks & $38.1(38.0-38.4)$ & $39.1(39.0-39.4)$ & $<0.0001$ \\
Weight at birth, grams & $3258.5 \pm 498.5$ & $3477.8 \pm 487.7$ & 0.04 \\
5' APGAR $<7$ & 0 & 0 & NA \\
Hypothermia & 0 & 0 & NA \\
RDS & 0 & $1(1.1)$ & 1.0 \\
TT & 0 & 0 & NA \\
Neonatal jaundice & $2(2.2)$ & $2(2.1)$ & 1.0 \\
NICU admission & $8(8.8)$ & $6(6.3)$ & 0.7 \\
\hline $\begin{array}{l}\text { GA }=\text { gestational age; RDS }=\text { Respiratory distress syndrome; TT }=\text { Transient tachypnea; NICU }=\text { Neonatal } \\
\text { intensive care unit. }\end{array}$ & &
\end{tabular}

\section{Discussion}

The results of this study indicate that prophylactic administration of betamethasone in elective cesarean section at 38 weeks presents similar neonatal respiratory outcomes and NICU admission than elective delivery at 39 weeks without fetal lung maturation. Based on evidence in this line, ACOG redefined term pregnancy as early $(37+0-38+6$ weeks $)$ and late $(39+0-40+6$ weeks $)$ since early-term population still presents a higher risk of adverse respiratory outcome. This recommendation was included in clinical guidelines of the Royal Australasian College of Obstetricians and Gynecologists and ACOG, suggesting that the elective cesarean sections should be postponed at 39 weeks [1] [2].

However, it is important to acknowledge that there is a group of pregnancy-related pathologies with specific indication of elective cesarean section at 38 weeks (mild intrahepatic cholestasis of pregnancy, previous cesarean section, total occlusive placenta with signs of placenta accreta, multiple cesarean section scars associated with rurality or late-onset pre-eclampsia). It is in this group of patients that the alternative of using prophylactic betamethasone exists, with the aim of preventing adverse neonatal respiratory outcome.

A major weakness of this study is the reduced sample size with a possible reduction on the study's power. Although the number of participants is relatively small, this study allows us to suggest that betamethasone prophylaxis is a valid alternative for elective cesarean section at 38 weeks, with similar risks of adverse respiratory outcome and NICU admission than deliveries at 39 weeks.

This conclusion is endorsed by Cochrane who concludes that antenatal corticosteroids at term in elective cesarean section reduce the risk of RDS (52\%), TT (57\%) and NICU admission (58\%) due to respiratory complications [3]. On the 
other hand, the results of the present study allow us to support the safety of antenatal betamethasone for pathologies that require delivery during the early-term period.

\section{Conclusion}

In conclusion, the present study reinforces the concept that betamethasone use in early-term deliveries is an indication that ensures an optimal perinatal outcome. Due to the small number of subjects participating in the study, new studies are necessary to share conclusions with more significant statistical power.

\section{Statement of Ethics}

This study has the authorization of the ethics committee of Hospital Clínico de la Universidad de Chile (Certificate No 01, January 8th, 2020).

\section{Author Contributions}

E.V.R. designed the study, wrote the document and supervised the database completion. A.S-M. performed statistical analyses and approved the final version of the document. P.S. and J.U. performed data collection, bibliographic review and co-wrote the document. E.V. performed medical charts review and collaborate in collecting neonatal data.

\section{Conflicts of Interest}

The authors declare no conflicts of interest regarding the publication of this paper.

\section{References}

[1] Committee on Obstetric Practice (2017) ACOG Committee Opinion Antenatal Corticosteroid Therapy for Fetal Maturation. Obstetrics \& Gynecology, 130, e102-e109. https://doi.org/10.1097/AOG.0000000000002237

[2] Gyamfi-Bannerman, C., Thom, E.A., Blackwell, S.C., Tita, A.T., Reddy, U.M., Saade, G.R., et al. (2016) Antenatal Betamethasone for Women at Risk for Late Preterm Delivery. New England Journal of Medicine, 374, 1311-1320. https://doi.org/10.1056/NEJMoa1516783

[3] Srinivasjois, R. and Silva, D. (2017) Antenatal Steroid Administration in Medically Uncomplicated Pregnancy beyond 37 Weeks of Gestation for Prevention of Neonatal Morbidities Prior to Elective Caesarean Section: A Systematic Review and Meta-Analysis of Randomized Controlled Trials. Journal of Maternal-Fetal \& Neonatal Medicine, 30, 1151-1157. https://doi.org/10.1080/14767058.2016.1205031

[4] Sotiriadis, A., Makrydimas, G., Papatheodorou, S. and Ioannidis, J.P. (2009) Corticosteroids for Preventing Neonatal Respiratory Morbidity after Elective Caesarean Section at Term. Cochrane Database of Systematic Reviews, No. 4, CD006614. https://doi.org/10.1002/14651858.CD006614.pub2

[5] Steer, P.J. (2005) Giving Steroids before Elective Caesarean Section. BMJ, 331, 645-646. https://doi.org/10.1136/bmj.331.7518.645

[6] Berthelot-Ricou, A., Lacroze, V., Courbiere, B., Guidicelli, B., Gamerre, M. and Si- 
meoni, U. (2013) Respiratory Distress Syndrome after Elective Caesarean Section in Near Term Infants: A 5-Year Cohort Study. Journal of Maternal-Fetal \& Neonatal Medicine, 26, 176-182. https://doi.org/10.3109/14767058.2012.733743

[7] Amiya, R.M., Mlunde, L.B., Ota, E., Swa, T., Oladapo, O.T. and Mori, R. (2016) Antenatal Corticosteroids for Reducing Adverse Maternal and Child Outcomes in Special Populations of Women at Risk of Imminent Preterm Birth: A Systematic Review and Meta-Analysis. PloS One, 11, e0147604.

https://doi.org/10.1371/journal.pone.0147604

[8] Morrison, J.J., Rennie, J.M. and Milton, P.J. (1995) Neonatal Respiratory Morbidity and Mode of Delivery at Term: Influence of Timing of Elective Caesarean Section. BJOG, 102, 101-106. https://doi.org/10.1111/j.1471-0528.1995.tb09060.x

[9] Stutchfield, P., Whitaker, R. and Russell, I. (2005) Antenatal Betamethasone and Incidence of Neonatal Respiratory Distress after Elective Caesarean Section: Pragmatic Randomized Trial. BMJ, 331, 662. https://doi.org/10.1136/bmj.38547.416493.06

[10] Nada, A.M., Shafeek, M.M., El Maraghy, M.A., Nageeb, A.H., Salah El Din, A.S. and Awad, M.H. (2016) Antenatal Corticosteroid Administration before Elective Caesarean Section at Term to Prevent Neonatal Respiratory Morbidity: A Randomized Controlled Trial. European Journal of Obstetrics \& Gynecology and Reproductive Biology, 199, 88-91. https://doi.org/10.1016/j.ejogrb.2016.01.026

[11] Miller, M. and Fanaroff, A. (2002) Respiratory Disorders in Preterm and Term Infants. Neonatal-Perinatal Medicine. Diseases of the Fetus and Infant. $7^{\text {th }}$ Edition, Ed. Mosby, St. Louis, 1025-1049.

[12] Perlman, J. and Kjaer, K. (2016) Neonatal and Maternal Temperature Regulation during and after Delivery. Anesthesia \& Analgesia, 123, 168-172.

https://doi.org/10.1213/ANE.0000000000001256

[13] Mitra, S. and Rennie, J. (2017) Neonatal Jaundice: Aetiology, Diagnosis and Treatment. British Journal of Hospital Medicine (London), 78, 699-704.

https://doi.org/10.12968/hmed.2017.78.12.699 